\title{
Hybrid SWOT-AHP Analysis of ICT Enabled Control System in the Process Industry - A Case Study
}

\author{
Jayalakshmi.B, \\ Research scholar, \\ Mechanical Department, Karpagam University, \\ Coimbatore, \\ Tamil Nadu,India \\ (Associate Professor, \\ Instrumentation and Control Engineering Dept, \\ NSS College of Engineering, \\ Palakkad, Kerala, India)
}

\author{
Pramod.V.R \\ Associate Professor, \\ Department of Mechanical Engineering \\ NSS College of Engineering, \\ Palakkad-8, Kerala, India
}

\begin{abstract}
With current increased applications of web-based management systems, the number of fatalities occasioned by human error in industrial plants has significantly reduced. Distributed control system used in industries for monitoring and control techniques offers reprieve to plant managers by offsetting the number of threats to plant operations through early detections and interventions. Even though open loop wireless control systems are used in modern industries, wireless technologies for closed loop control systems are not yet implemented in industries. The present study aims to analyze the possibility of implementing wireless remote control system in industries with the help of SWOT AHP. Appropriate SWOT analysis results in the formulation of suitable policies by the process industry to build up its strengths, eradicate its weakness and exploit its opportunities to pawn the threats. Analytical Hierarchy process (AHP) is an ideal tool for strategy preparation in many organizations. The proposed SWOT-AHP framework was implemented and evaluated for a water and sewerage plant. The study concludes that SWOT-AHP methodology is a viable and effective tool in evaluating complex decision making on the suitability of implementing ICT enabled wireless control system in a plant.
\end{abstract}

\section{Key words}

Control valve, ICT, AHP, SWOT, Case study

\section{INTRODUCTION}

Implementation of ICT based control systems in management of plant operations is the fastest growing and most dynamic ventures in the industry today. Organizations that have implemented ICT based control systems are able to identify and mitigate risks to plant operations well in advance to avert disasters [15].In addition, an organization is able to identify opportunities for investment and formulation of strategies that would improve the organizational performance. In recent times, majority of industries have adopted certain protocols that facilitate data access from remote subunits via wireless technologies. Control systems based on internet applications have been widely adopted in this respect by combining both internet and wireless communication technologies for monitoring and controlling plant operation processes [14].

However, Web based applications are prone to connectivity delays and data loss through hacking among other challenges[13]. To overcome such challenges, Information
Communication Technology (ICT) has emerged as a mature technology in remote control of valves in plant operations. Despite the achievements of ICT use in information control, the notion of implementing ICT based process control system in industry is shrouded by diverse and unforeseeable internal and external environmental conditions and requires feasibility studies to identify environmental factors specific for each industry [2].

Within the present study perspectives, application of ICT has expanded beyond exchange of tacit knowledge and social interaction. The technology currently has the capacity of remote monitoring and control of operations between systems and equipment.ICT enabled control valve, being a wireless control system, consumes only a lesser space and not concerned about distance between control room and process. Other advantages of offering ICT based control valves are real time operation, greater flexibility and mobility for users, cheap installation \& maintenance cost, better efficiency, user friendly, enhancement of production, reliability and high speed of response. With the introduction of a highly secure system, hacking can be reduced to a notable extent when compared to Internet based process control systems. Controlling an industrial process from geographical diverse location is a great process industrial development using ICT. Adoption of such a technology can be a shot in the arm for modern industry. However, very little research work has been done to date aimed at developing systematic design methods using this technology or for the design of ICT based wireless process control systems. The lack of implementation of ICT based remote control in the industries prompted the authors to propose the present work.

The aim of the present study is to analyze the feasibility of remote monitoring and control of plants in industries using wireless ICT based process control system with the help of a hybrid SWOT-AHP framework. The methodology used in feasibility analysis combines Strengths, Weaknesses, Opportunities and Threats (SWOT) matrix and Analytic Hierarchy Process (AHP). The SWOT matrix evaluates both internal and external environment factors. AHP is a multicriteria decision-making approach based on pair-wise factor comparisons and their prioritizations from calculated Eigenvalues. The hybrid method defines the criteria for decision making by considering interrelationships and decision alternatives and results are used in identification of best 
strategies for implementation of ICT based process control system in remote monitoring and control of plants. In this work, a model case study of a water and sewerage plant is used to illustrate the role of ICT control wireless systems in water metering control and management to avoid wastages and improve efficiency [1]. The present study deduced that the implementation of ICT based process control system in a plant has a greater probability of success. Findings from this study also revealed that a hybrid SWOT-AHP analysis framework is an effective decision support methodology by empowering the decision maker in thinking over the weights of SWOT factors.

\section{Materials and methods: SWOT AHP Methodology}

SWOT analysis as a tool is commonly used for analysis of external and internal environments with aim of achieving a systematic approach of decision making from the prevailing conditions. External environment refers to conditions under which the organization operates including threats and opportunities. Internal environment refers to strengths and weakness of the organization within its business operations. Combined analysis of external and internal environment accounts for the organization's scale of values simply denoted as SWOT (Strengths, Weaknesses, Opportunities, and threats) factors [6].

A SWOT-AHP hybrid framework allows for systematic evaluation of SWOT factors depending on their intensities thus adding value to SWOT analysis. The value added is obtained from pair-wise comparisons between SWOT factors utilizing Eigen value calculation technique. The Eigen values offer appropriate means of examining, prevailing and predictive situations in a more comprehensive manner [11]. SWOT-AHP analysis has been successfully implemented in areas such as evaluation of investment opportunities [3], allocation of appropriate service concepts to various segments of IT market [7], optimizations of research and development (R\&D) projects [5], in the evaluation of ERP systems [12], and to choose the best strategies for the successful implementation of egovernment in Saudi Arabia [17]. AHP and ANP methods are used for the prioritization and comparison of SWOT factors [16]. The model case study reported in the present work details the application of SWOT-AHP hybrid model for the implementation of remote monitoring and control of plant using ICT. The combined methodology facilitates the generation of priorities among identified SWOT factors and decision alternatives.

\subsection{Case study}

$\mathrm{XYZ}$ is a water and sewerage plant situated in Mysore, India. It was incorporated in 2001. Wired systems are used for monitoring and controlling the process, thus consume more space. The XYZ plant officials have an idea to innovate the plant to get enough space, better control and efficiency, greater flexibility and optimum plant operation. When the authors approached plant officials with their proposal, they instantly arranged for a model case study as a prerequisite for the implementation of the proposal. The plant officialsof $\mathrm{XYZ}$ are tasked with multi-criteria decision-making scenarios for selecting the best approach of implementing remote monitoring and control of plant operations using ICT. Our study proposes a systematic approach that presents judgment on the best implementation strategy. To implement the project, data on user perspectives have to be generated.

\subsubsection{Data collection}

We identified ten experts with rich experience and deep knowledge in the XYZ plant management for the study. Their perspectives were collected using a semi-structured questionnaire concerning implementation of ICT based process control system. From their opinions, a SWOT matrix was developed outlining key internal and external environment factors (see Appendix A). To pair the comparisons, the questions were designed requiring the selected respondents to: 1) compare two factors in respect to implementation of ICT based control systems, 2) rate each individual factor on the basis of strength and opportunity or weakness and threat[10]. The rating scale generates relative weights of each SWOT factor with comparisons as the input followed by calculation of Eigen-values in order to obtain global priorities for each paired SWOT factor [8].

\subsubsection{Prioritization of SWOT factors}

Calculation of global priority of SWOT is as follows: $\mathrm{G}_{i}=\mathrm{S}_{i} \mathrm{O}_{i} /$ $\mathrm{W}_{i} \mathrm{~T}_{i}$ Where: $\mathrm{G}_{i}=$ Overall priority for strategy $i$

$\mathrm{S}_{i}, \mathrm{O}_{i}, \mathrm{~W}_{i} \mathrm{andT}_{i}=$ Eigen values for Strengths, Opportunities, Weaknesses, and Threats for strategy $i$ driven by SWOT factors

To calculate SWOT factor intensities, a rating scale is assigned for ranking/hierarchy of strategies [9] and the desirability index $\left(\mathrm{D}_{\mathrm{i}}\right)$ computed as follows: $D_{i}=\sum_{j=i}^{n} G_{j} R_{i j}$, Where $G_{j}$ is the Global weight for $j^{\text {th }}$ SWOT factor

$R_{i j}$ - the degree of interrelationships between $i^{\text {th }}$ strategy and $j^{\text {th }}$ SWOT factor, $n-$ no. of SWOT factors. Synthesis of the global priorities involves multiplication of criteria-specific priorities with criterion weight followed by summing up the results in order to obtain the overall global priority.

\section{SWOT-AHP HIERARCHY ANALYSIS}

The SWOT analysis tool has been used widely in decision criteria as described in the literature review. In the present study, we applied the SWOT-AHP hybrid to effectively select the decision criteria model based on the respondent's viewpoints as explained under the data collection section. A systematic approach described in the methodology section was used for the case study analysis. The SWOT-AHP framework was used for conducting a detailed situational assessment and fitness between SWOT factors and decision-making criteria to be adopted. 
Table 1.Analytical Hierarchy Process Analysis of Strengths of ICT based process control system

\begin{tabular}{|l|l|l|l|l|l|l|}
\hline Strengths & S1 & S2 & S3 & S4 & S5 & $\begin{array}{l}\text { Eigen } \\
\text { value }\end{array}$ \\
\hline S1 & 1 & 5 & 9 & 7 & 5 & 0.56 \\
\hline S2 & $1 / 5$ & 1 & 7 & 7 & 1 & 0.20 \\
\hline S3 & $1 / 9$ & $1 / 7$ & 1 & $1 / 3$ & $1 / 7$ & 0.03 \\
\hline S4 & $1 / 7$ & $1 / 7$ & 3 & 1 & $1 / 3$ & 0.06 \\
\hline S5 & $1 / 5$ & 1 & 7 & 3 & 1 & 0.157 \\
\hline
\end{tabular}

.The Eigen value is calculated by dividing each of the elements in the row by the sum of the corresponding column in the matrix. The results are graphically plotted as shown in chart 1 .

\section{Chart 1 Eigen values for Strengths}

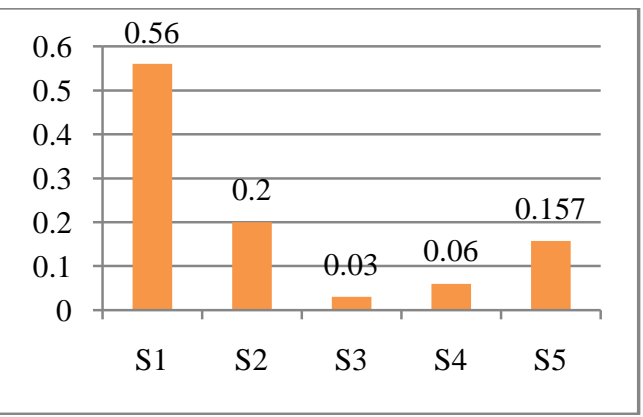

Table 2: Analytical Hierarchy Process Analysis of Weaknesses of ICT based process control system

\begin{tabular}{|l|l|l|l|l|l|l|l|}
\hline Weaknesses & W1 & W2 & W3 & W4 & W5 & W6 & $\begin{array}{l}\text { Eigen } \\
\text { value }\end{array}$ \\
\hline W1 & 1 & $1 / 5$ & $1 / 7$ & 1 & 3 & $1 / 5$ & 0.06 \\
\hline W2 & 5 & 1 & 3 & 7 & 7 & 3 & 0.41 \\
\hline W3 & 7 & $1 / 3$ & 1 & 5 & 5 & 3 & 0.27 \\
\hline W4 & 1 & $1 / 7$ & $1 / 5$ & 1 & 3 & $1 / 3$ & 0.06 \\
\hline W5 & $1 / 3$ & $1 / 7$ & $1 / 5$ & $1 / 3$ & 1 & $1 / 5$ & 0.03 \\
\hline W6 & 5 & $1 / 3$ & $1 / 3$ & 3 & 5 & 1 & 0.16 \\
\hline
\end{tabular}

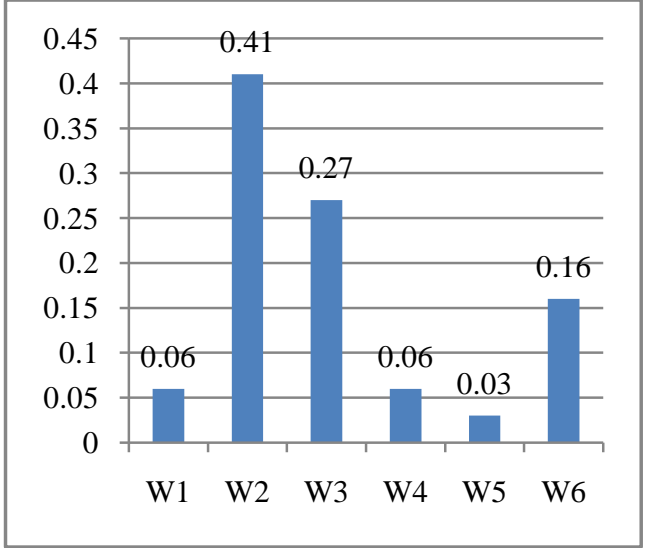

Table 3Analytical HierarchyProcess Analysis of Opportunitiesof ICT based process control system.

\begin{tabular}{|l|l|l|l|l|l|l|}
\hline Opportunities & O1 & O2 & O3 & O4 & O5 & $\begin{array}{c}\text { Eigen } \\
\text { value }\end{array}$ \\
\hline O1 & 1 & $1 / 3$ & 3 & $1 / 5$ & 1 & 0.12 \\
\hline O2 & 3 & 1 & 5 & 1 & 3 & 0.33 \\
\hline O3 & $1 / 3$ & $1 / 5$ & 1 & $1 / 5$ & 1 & 0.07 \\
\hline O4 & 5 & 1 & 5 & 1 & 5 & 0.41 \\
\hline O5 & 1 & $1 / 3$ & 1 & $1 / 5$ & 1 & 0.09 \\
\hline
\end{tabular}

Chart 3: Eigen values of Opportunities

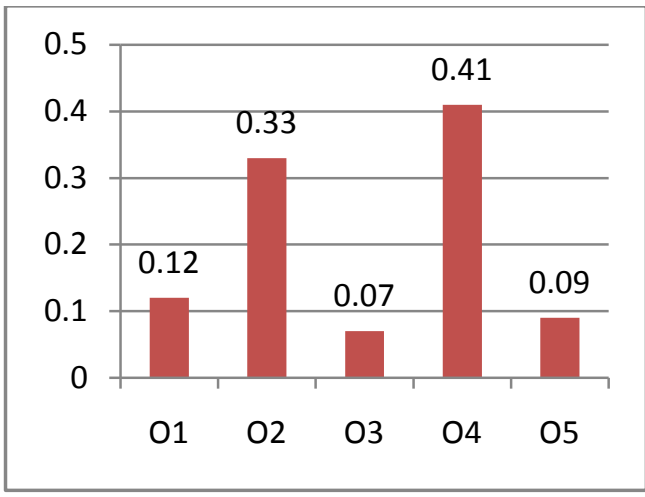

Chart 2: Eigen values of Weaknesses 
Table 4: Analytical Hierarchy Process Analysis of Threats of ICT enabled Process control system

\begin{tabular}{|l|l|l|l|l|l|l|}
\hline Threats & T1 & T2 & T3 & T4 & T5 & $\begin{array}{l}\text { Eigen } \\
\text { value }\end{array}$ \\
\hline T1 & 1 & $1 / 5$ & 5 & 7 & 1 & 0.19 \\
\hline T2 & 5 & 1 & 9 & 9 & 1 & 0.45 \\
\hline T3 & $1 / 5$ & $1 / 9$ & 1 & 2 & $1 / 9$ & 0.04 \\
\hline T4 & $1 / 7$ & $1 / 9$ & $1 / 2$ & 1 & $1 / 7$ & 0.03 \\
\hline T5 & 1 & 1 & 9 & 7 & 1 & 0.29 \\
\hline
\end{tabular}

\section{Chart 4: Eigen values of Threats}

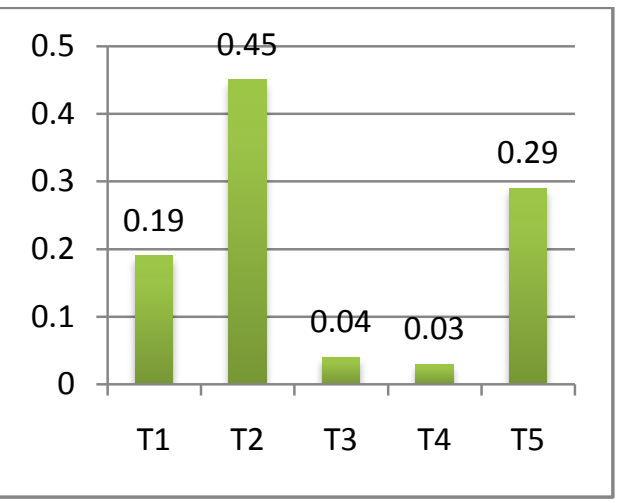

After calculation and totalizing the Eigenvectors, evaluation of the SWOT group intensities based on the last weight comparisons reflects the value of greater importance in respect to the overall aim at the top of the hierarchy. Global priority can be evaluated using the equation stated for prioritization of SWOT factors.

\section{Table 5 Factor intensity}

\begin{tabular}{|l|l|l|l|}
\hline SWOT factors & $\begin{array}{l}\text { Effective } \\
\text { Implementation } \\
\text { of ICT based } \\
\text { process control } \\
\text { system. }\end{array}$ & $\begin{array}{l}\text { User } \\
\text { perspectives }\end{array}$ & $\begin{array}{l}\text { Global } \\
\text { priority }\end{array}$ \\
\hline Strengths & 0.16 & 0.26 & 0.22 \\
\hline Weaknesses & 0.26 & 0.16 & 0.26 \\
\hline Opportunities & 0.26 & 0.26 & $\mathbf{0 . 3 0}$ \\
\hline Threats & 0.16 & 0.26 & 0.22 \\
\hline
\end{tabular}

Intensities key: 0.42 (Very High); 0.26 (High); 0.16 (Medium); 0.10 (Low); 0.06 (Very Low)

\section{Chart 5: Overall SWOT factors value}

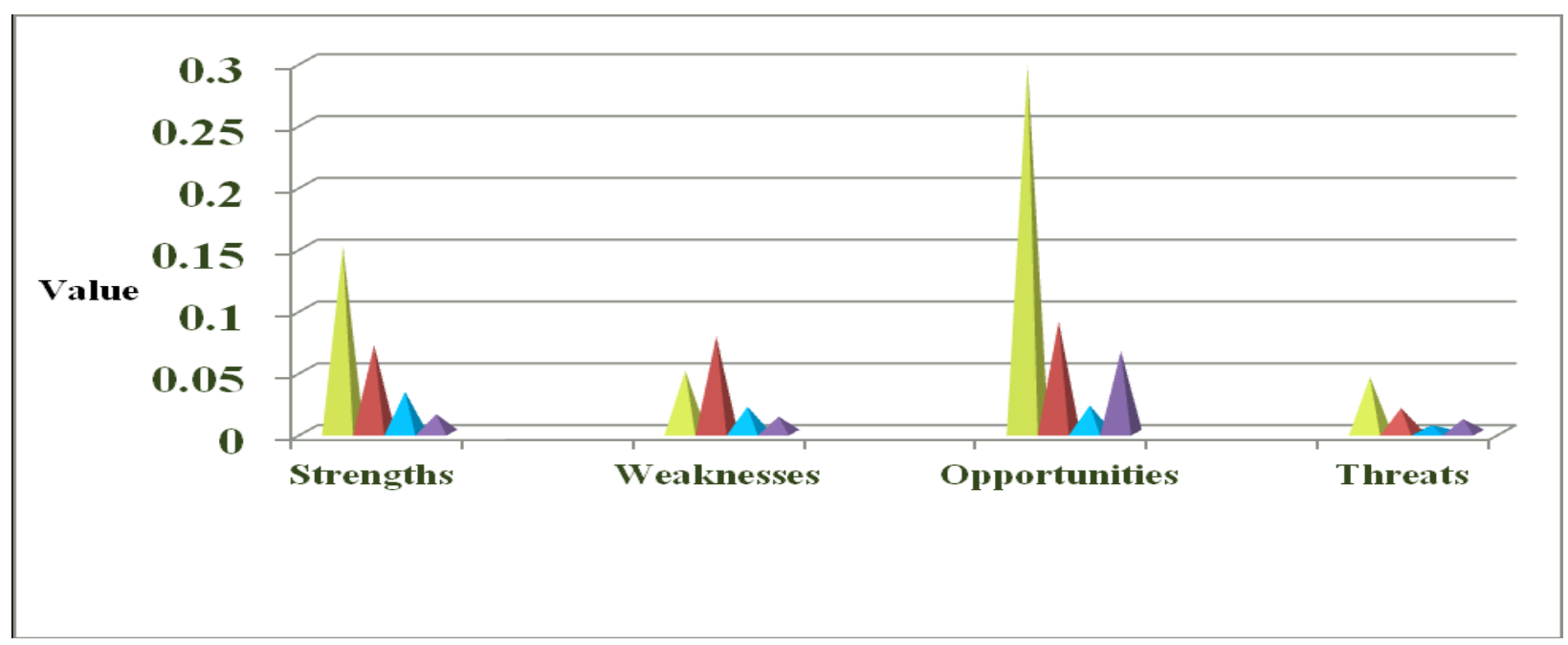




\section{RESULTS AND DISCUSSION}

Based on the identified SWOT factors and their global priority index, we proposed three strategies are as follows:

$\mathrm{ST}_{1}$ - Design and Implementation of ICT based wireless process control system for remote monitoring and control. From Figure 3 , it is clearly evident that both Opportunities and Strength outweigh Threats and Weaknesses. It was also observed from Eigen vector calculations that strengths are the most valuable factors in implementation of the ICT-based control valve system for monitoring and control of water metering. The combined success factors for $\mathrm{ST}_{1}$ are $(\mathrm{S} 1, \mathrm{~S} 2, \mathrm{O} 2, \mathrm{O} 4, \mathrm{~W} 1, \mathrm{~W} 5$, and T3). Strength 1 and 2 particularly renders the remote controlled metering process cost-effective and sustainable by the plant in management of offsite subunits. The opportunity factors $\mathrm{O} 2$ and $\mathrm{O} 4$ significantly favor implementation of ICTbased process control system in the plant in order to realize the proposed objective.

\subsection{Decision alternatives}

$\mathrm{ST}_{2}$ - Consolidation of existing IT/IS technologies in order to improve the exchange of tacit knowledge in the plant processes. This strategic decision is only viable for the water and Sewerage Company if Weakness 3 and Threat 3 (W3, T3) remain low with respect to the study objective in order to compliment benefits from Strength 5 (S5) and opportunities1 and $4(\mathrm{O} 1, \mathrm{O} 4)$. Alternatively the organization can outsource the metering services to a third party and $\mathrm{ST}_{3}$ - Tendering management of water metering in a remote location to a thirty party (S1, W2, T1, T2), however, threat factor 2 (T2) with over $40 \%$ Eigen value poses the greatest challenge to implementation of this strategic decision.

As Figure 3 illustrates, clearly there exists greater strength and opportunity factors with significantly fewer threats and weakness that can contribute to failure of $\mathrm{ST}_{1}$. Therefore, the present study deduced that the proposed implementation of ICT-based process control system in a plant has a greater probability of success. Findings from this study also revealed that a hybrid SWOT-AHP analysis framework is an effective decision support methodology by empowering the decision maker in thinking over the weights of SWOT factors.

\section{CONCLUSION AND SUGGESTIONS FOR FUTURE WORK}

The importance of implementing ICT based wireless process control systems in industrial plant is evident. Without ICT advancement, very few structural changes would have been witnessed in corporate organizational management..The systematic SWOT-AHP analysis approach proposed herein on the role of ICT based wireless control systems encourage broad scale adoption of the technology in remote monitoring and control of plants. It is clear that there exist greater strength and opportunity factors with significantly fewer threats and weakness that can contribute to failure of $\mathrm{ST}_{1}$. Therefore, the present study deduced that the proposed implementation of ICT-based control system in a plant has a greater probability of success. The population sample was drawn from localized settings. Therefore future research is suggested to cover multisector analysis for implementation of ICT-based wireless process control systems.

\section{REFERENCE}

[1] Hill, T and Westbrook, R. "SWOT analysis: it's time for a product recall”,Long Range Planning, 1997,30.1, 46-52.
[2]Iraj, Hamed, Mohammad, MP and Armaghan,Heidarzade.“Applying Multi-Criteria Decision Methods and SWOT Factors to Analyze the Role of Information Technology in Industry Development in Iran”,Journal of Applied Sciences, 2008:8, 2983-2990.

[3] Kengpol, A and O'Brien, C. "An Analytical Network Process for the Evaluation of Investment in Time Compression Technology",Proceedings of the 11th Annual Meeting of Production and Operations Management Society, San Antonio; 2000.

[4] Masozera, MK, Alavalapati, JRR, Jacobson, SK and Shrestha, RK. "Assessing the suitability of community-based management for theNyungwe Forest Reserve, Rwanda",Forest Policy and Economics, (2006): 8, 206-216.

[5] Meade, LM and Presley, A. "R\&D Project Selection Using the Analytic Network Process",IEEE Transactions on Engineering Management, (2002):49, 59-67.

[6] Pasonen, M, Kurttila, M, Kangas, J, Kajanus, M and Heinonen, P. "Assessing the priorities using A'WOT among resource management strategies at the Finnish forest and park service", $\quad$ Forest Science, (2000):47.4, 534-541.

[7] Partovi, FY. "An analytic model to quantify strategic service vision," International Journal of Service Industry Management, (2001):12,476-499.

[8] Saaty, T.L.The Analytic Hierarchy Process: Planning, Priority Setting, Resource Allocation, McGraw-Hill, Inc., 1980.

[9] Saaty, T.L.Theory and Applications of the Analytic Network Process: Decision Making with Benefits, Opportunities, Costs, and Risks. Pittsburgh: RWS Publications, 2005.

[10] Saaty, TL."Decision making with the analytic hierarchy process", International Journal of $[\quad$ Services Sciences (IJSSCI), (2008):1.1, 83-98.

[11]Shrestha, RK, Alavalapti, JRR and Kalmbacher, RS. "Exploring the potential for silvopasture adoption in south-central Florida: an application of SWOT-AHP method," AgricultureSystems,(2004):81,185-199.

12].Shyur, H. "A Semi-Structured Process for ERP Systems Evaluation: Applying Analytic Network Process",Journal of eBusiness, (2003):5, 1:33-49

[13]Syed, M. Ahsan, AmjadFarooq, M. Shahbaz, M. JunaidArshad, M. Aslam. "Scaling Technique for Web Based Management Systems in Bioinformatics", Life Science Journal,(2012):9,3, 1-5.

[14].Thompson, HA. "Wireless and Internet communications technologies for monitoring and control", Control Engineering Practice,(2004):12.6, 781-791.

[15]Wickramasinghe, Vasantha and Shin-ei, Takano. "Application of Combined SWOT and Analytic Hierarchy Process (AHP) for Tourism Revival Strategic Marketing Planning: A Case of Sri Lanka Tourism",Journal of the Eastern Asia Society for Transportation Studies,(2009):8. 
[16] Ali GÖRENER,“Comparing AHP and ANP: An Application of Strategic Decisions Making in a Manufacturing Company",International Journal of Business and Social Science(2012),Vol. 3 No. 11;pg 194-208.
[17]SalehAlshomrani and ShahzadQamar.: Hybrid SWOT-AHP Analysis of Saudi Arabia E-Government. International Journal of Computer Applications 48(2):1-7, June 2012.

\section{Appendix A: SWOT analysis matrix}

\begin{tabular}{|c|c|}
\hline$\underline{\text { Strengths }}$ & Weakness \\
\hline $\begin{array}{l}\text { S1 Hazard free operations. } \\
\text { S2 Employee satisfaction } \\
\text { S3 Better control. } \\
\text { S4 Low maintenance cost. } \\
\text { S5 Increased efficiency in plant operations }\end{array}$ & $\begin{array}{l}\text { W1 Narrow band of operating frequency } \\
\text { spectrum } \\
\text { W2 Increased adaptation and administrative } \\
\text { costs } \\
\text { W3 Initial investment is high. } \\
\text { W4 Competition from the conventional methods } \\
\text { of control } \\
\text { W5.Information Security is a problem. } \\
\text { W6. control action delay }\end{array}$ \\
\hline $\begin{array}{l}\text { Opportunities } \\
\text { S1 High innovation leads to business } \\
\text { expansion } \\
\text { S2 Optimum plant operation. } \\
\text { S3 Intelligent Automation \&Information } \\
\text { Management systems } \\
\text { S4 Dynamic and Reliable Technology. } \\
\text { S5 Profit margins will be high. }\end{array}$ & $\begin{array}{l}\text { Threats } \\
\text { T1 Resistance to change. } \\
\text { T2 Fear of information system break down. } \\
\text { T3 Any problem to the central server may cause } \\
\text { loss of data resulting in closure of all operations, } \\
\text { until the problem is rectified. } \\
\text { T5 Lack of funds. }\end{array}$ \\
\hline
\end{tabular}

